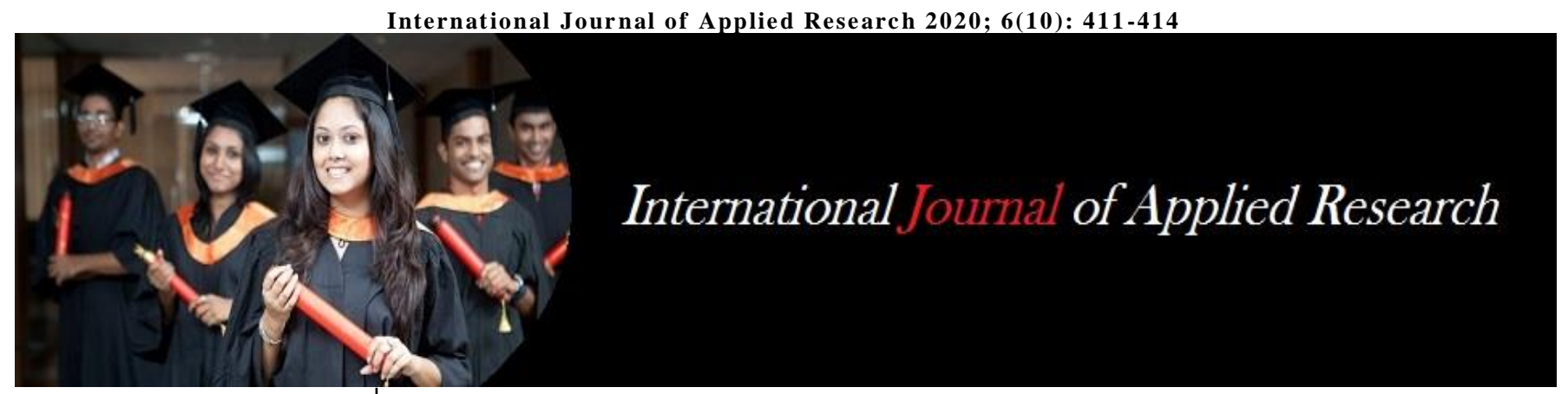

ISSN Print: $2394-7500$

ISSN Online: 2394-5869

Impact Factor: 5.2

IJAR 2020; 6(10): 411-414

www.allresearchjournal.com

Received: 15-08-2020

Accepted: 17-09-2020

Sangeeta Suman

Research Scholar, Department

of Education, Babasaheb

Bhimrao Ambedkar

University, Lucknow, Uttar

Pradesh, India
Corresponding Author:

Sangeeta Suman

Research Scholar, Department

of Education, Babasaheb

Bhimrao Ambedkar

University, Lucknow,

Uttar Pradesh, India

\section{A comparative study of stress level in hearing impaired and normal students}

\section{Sangeeta Suman}

DOI: https://doi.org/10.22271/allresearch.2020.v6.i10g.7337

\begin{abstract}
The study attempted to determine the comparative study of stress level of Hearing Impaired (HI) and normal students. For the present study the sample of 160 students has been selected for the age group of 14 to 18 years old. In the present study purposive sampling technique has been used. The researcher has tried to investigate the level of stress among students of hearing impaired and normal. There were a lot of problem to communicate with them because of language barrier. They can understand with their own style i.e. sign language. Descriptive survey method is suitable for the study. Finding of the study reveals that stress level of hearing impaired students has more in compare to normal students because of some depressive symptoms. Prevention and treatment can give them positive direction in their life.
\end{abstract}

Keywords: Stress level, hearing impairment, normal students

\section{Introduction}

Children are unique. If we observe a busy playground, we see a spectacle of this uniqueness. Some children move more quickly and with better coordination than others. Some children are surrounded by admiring friends whereas others sit alone at some distance. The differences we observe on the playground are more obvious than those we might see inside the classroom. The field of special education is concerned with children who deviate from normal children to the extent that matters very much for learning in schools and successfully elsewhere. Hearing impairment is one of the serious anomalies next to visual impairment. Hearing impairment leads to hearing disability or loss of hearing. Hearing disability or loss of hearing may range in severity from mild to moderate and moderate to profound. A person may deaf or hard-of-hearing it totally depending on the degree of hearing loss. The hearing impaired (HI) subjects are classified into two groups such as the deaf, and the hard-ofhearing. The total inability to hear is called deafness. The deaf are those who, even with the best auditory training, cannot learn to understand speech mainly through hearing. During developmental stages of student life many changes occur. Behavioral changes occur in different developmental stages like physical, emotional, social and cognitive stage. Peevish and acrimonical behavioral pattern change is very common in emotional stage.

Stress comes through availability of resources they deal with the event and circumstances in day to day life (Seiffge-weidermann, Fenter, Aegenheister \& Poeblau, 2001) ${ }^{[13]}$. Most of students get frustrated in their circumstances. Pragmatic behavior, a facet of good speech integibility, we found that in mainstream, there are integration among normal students having

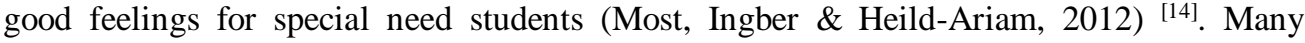
difficulties may incur frustration and stress in students. This is a scant research to examine the stress in hearing impaired student and normal students.

\section{Review literature}

Notash \& Elhamkia (2016) ${ }^{[8]}$ in this paper titled "Comparing loneliness, depression and stress in students with hearing impaired and normal students studying in secondary schools of Tabriz" the study was conducted to compare the feeling of loneliness, depression, and stress among hearing impaired and normal students of Tabriz city. The sample size is thirty students, selected by convenience sampling method and Casual comparative study has been opted. MANCOVA was used to analyze the hypothesis. The result shows significant difference between them. 
Eschenbeck, Gille, Heim-Dreger, Schock \& Schott (2017) ${ }^{[4]}$ in this paper titled "Daily Stress, Hearing-Specific Stress and Coping: Self-reports from Deaf or Hard of Hearing Children and Children with Auditory Processing Disorder" want to evaluate stressor and coping strategies in 70 children who are deaf. With help of questionnaire tool, everyday stressor and coping behavior were examined. Reports were comparing with normative data. The result found that girls scored high, in seeking social support whereas boys were scoring high, in amount of media use as a way of coping.

Zaidman-Zait \& Dotan (2017) ${ }^{[12]}$ in this paper titled "Everyday Stressors in Deaf and Hard of Hearing Adolescents: The Role of Coping and Pragmatics" mixed method approach is used to examine problems among deaf in their various life situations. Thirty deaf adolescents, has filled questionnaires about everyday stressors and coping, and thirteen of which were interviewed about their daily life problems. Teachers evaluated the pragmatic skills of each participant via communication assessment tool. The questionnaire result showed that deaf adolescents perceived greatest stress related to the future, peers, and school. Low level of stress was experienced to parents, leisure and romantic relationships. Importantly, lower pragmatic abilities and increased level of withdrawn, coping style were associated with higher perceiving stress. The conclusion of the study is on various ways in which schools, teachers, and professionals can insure prevention and interventional efforts for them to support deaf adolescents.

Czyz (2019) ${ }^{[3]}$ in this paper titled " The Level of stress and Coping stress styles of polish students with Hearing Impaired" were study to evaluate the level of stress of parents having hearing impaired children and find out the degree of association with hearing loss. For this a cross sectional study conducted at KGMC, medical college, U.P., Lucknow. The convenient sampling method is used, children at the age of 1 to $10 y r s$ and their parents. Qualitative as well as quantitative method is applied chi square test, SD and percentage has been calculated. The result found that there is severe stress in parents and significant association with stress of father raises the possibility of lack of awareness and neglect behavior.

Choudhury (2019) ${ }^{[2]}$ in this paper titled "Hearing Loss A Triggering Factor to Depression: A Systematic Review" the present study was conducted to assess the comprehensiveness and trend of various studies related to Hearing loss, individual leading depression by using diversified online data basis from various resources. This is the systematical review of multiple database exploration i.e. hard of hearing, stress and symptoms of depression, hearing impairment, depression, deaf. This study is a critical analysis of the study. Study shows considerable depressing symptom among individual with hearing loss and suicidal thoughts.

Kumari, Tiwari \& Kumar (2020) ${ }^{[5]}$ the purpose of the paper titled "Prevalence of stress among parents having Hearing Impaired child in North India" focused on stress and Coping with stress of profound hearing loss. The goal of the study is definition of level of stress, identification of styles using coping with stress, revealing and correlation between stress levels and styles of coping stress. The sample size is 76 students of the age group 16- 26 yrs. For analysis of results descriptive statistics and parametric test: U Mann Whitney, ANOVA and Kruskal Wallis and analysis of regression were used. The result indicates level of stress is different, no connection between stress and gender. The most frequent style is concentrating on task.

\section{Variables}

Hearing Impaired and normal students are dependent variable whereas stress is an independent variable through which researcher wants to know the comparison.

\section{Methodology}

Survey research method is found suitable for the present study. Survey research method is commonly used method of collecting information about a population of interest.

\section{Sample \& Sampling Techniques}

A Sample of 160 students were selected randomly by using purposive sampling technique from various schools in Lucknow. In which three Hearing Impaired schools and two private schools were selected. Survey method is found suitable for use to collect the data for research.

\section{Statistical Techniques \\ Descriptive Statistics: Mean, SD, Percentage. \\ Inferential Statistics: ' $\mathrm{t}$ ' Test.}

\section{Research Tools \\ Stress Scale}

The investigator has employed the standard tool of stress scale developed by Vijaya Lakshmi and Shruti Narain. Stress is considered to be a key factor affecting mental health and high level of stress is associated with depression and suicidal attempts (Nolen-Hoeksema, 2004). One recent study found that adolescents who engaged in suicide ideation were more likely to have experienced negatively life events in the past years than the adolescents who did not engage in suicide ideation (Liu and Tein, 2005). After extensive review of literature, four dimensions were included in this scale consists of 40 items. The test re-test reliability was calculated and was found to be 0.82 , which was significant at 0.01 level. The resulting validity coefficient was 0.72 .

\section{Objectives of the study}

1) To study the stress level of Hearing Impairment and Normal students.

2) To study the stress level of Hearing Impaired and Normal girls.

3) To study the stress level of Hearing Impaired and Normal boys.

\section{Hypothesis}

1) No significant difference exists in the stress level of Hearing Impaired and Normal students.

2) Significant difference does not exist in the stress level of Hearing Impaired and Normal girls.

3) There is no significant difference in the stress level of Hearing Impaired and Normal boys.

\section{Recommendation and Limitation}

The study is restricted to a district of U.P. in Lucknow, to get the result more generalized with higher reliability and validity it is recommended to be conducted in other geographical area. Only one dimension is consider i.e. stress. The selected sample for the study is hearing impaired 
students only, for further researches many other sample may get select. There are lot of researches on parental stress of hearing impaired students but found few researches on hearing impaired students. For increasing external validity, future research is to be conducted with higher sample size.

\section{Analysis of data \\ Hypotheis-1}

1. $\mathrm{H}_{0}$ : No significant difference exists in the stress level of Hearing Impaired and normal students

There are two groups of hearing impaired and normal students, the data were tabulated and analyzed with help of t-test the result are:

\begin{tabular}{|c|c|c|c|c|c|}
\hline Sample & $\mathbf{N}$ & M S.D. & Df & t-value & Significance level \\
\hline Hearing impaired & 80 & 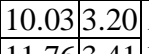 & & 3.32 & Significant \\
\hline Normal students & 80 & \begin{tabular}{|l|l|}
11.76 & 3.41 \\
\end{tabular} & 150 & & \\
\hline
\end{tabular}

From the above it is evident that ' $t$ ' value 3.32 is not significant at 0.05 level with $\mathrm{df}=158$. It reflects that mean score of level of stress between normal and hearing impaired are not differing significantly. In this context the Null hypothesis, "No significant difference exists in the stress level of Hearing Impaired and normal students." is rejected. Therefore it may be said that stress level is different in students Hearing Impaired and Normal students. Students having hearing impairment have more stress compare to normal students. The study of Notash and Elhamkia, $2016^{[8]}$ result support the result.

\section{Hypotheis-2}

2. Ho: No significant difference exists in the stress level of Hearing Impaired and Normal girls.

There are two groups of normal and hearing students, the data were tabulated and analysed with help of t-test the result are:

\begin{tabular}{|c|c|c|c|c|c|c|}
\hline Sample & $\mathbf{N}$ & $\mathbf{M}$ & S.D. & Df & t-value & Significance level \\
\hline HI Girls & 40 & 9.78 & 3.416 & 78 & \multirow{2}{*}{3.27} & Significant \\
\hline Normal Girls & 40 & 12.40 & 3.740 & & & \\
\hline
\end{tabular}

From the above it is evident that ' $t$ ' value 3.27 is significant at 0.05 level with $\mathrm{df}=78$. It reflects that mean score of are not differing significantly. In this context the Null hypothesis, significant difference does not exists in the stress level of Hearing Impaired and Normal girls is rejected. Therefore it may be said that stress level is different in Hearing Impaired and normal girls. Hearing impaired girls having more stress in compare to normal girls.

\section{Hypothesis-3}

3. $\mathrm{H}_{0}$ : There is no significant difference in stress level of $\mathrm{HI}$ and normal boys.

There are two groups of hearing impaired and normal boys, the data were tabulated and analyzed with help of t-test the result are:

\begin{tabular}{|c|c|c|c|c|c|c|}
\hline Sample & N & M & S.D. & df & t-value & Significance level \\
\hline HI Boys & 40 & 10.28 & 3.004 & \multirow{2}{*}{78} & \multirow{2}{*}{1.27} & \multirow{2}{*}{ Not Significant } \\
\hline Normal Boys & 40 & 11.13 & 2.954 & & & \\
\hline
\end{tabular}

From the above it is evident that ' $t$ ' value 1.27 is not significant at 0.05 level with $\mathrm{df}=78$. It reflects that mean score of level of stress between normal and hearing impaired are not differing significantly. In this context the Null hypothesis, there is no significant difference in the stress level of Hearing Impaired and normal boys, is accepted. Therefore it may be said that hearing impaired boys and normal boys have approximately same stress level.

\section{Interpretation of Result}

1. On behalf of above statistical analysis, result shows the significant value is greater than table value then we reject the null hypothesis, means can say that stress level is different in Hearing Impaired and normal students.

2. Statistical value is greater than tabulated value the null hypothesis is rejected, means there is some difference in stress level of Hearing Impaired and normal girls.

3. Statistical value is less than tabulated value the null hypothesis is accepted, it means stress level is same in Hearing Impaired and normal boys.

\section{Conclusion}

In the present study researcher was able to establish the stress level comparison in Hearing Impaired Students and Normal Students. There are many problems faced by Hearing Impaired students. They reported higher social and practical problems as compared to normal people. Still they were more adaptive with their circumstances and are happy with themselves. There are some challenges faced by researcher to communicate with them previously but very soon students were actively participated when they understand the questions. Thus it is suggested that proper direction and rehabilitation is able to mitigate their stress and motivate them to drawn out their best from them.

\section{References}

1. Abbas F, Rafque U, Mazid S. Stress level of parents of Hearing Impaired children. Journal of Education and Practice 2013;4(26):69-77.

2. Choudhury M. Hearing Loss A Triggering Factor to Depression: A Systematic Review. Scholarly Journal of Otolaryngology 2019;2(3):145-149. DOI: 10.32474/SJO.2019.02.000137.

3. Czyz AK. The Level of stress and Coping stress styles of polish students with Hearing Impaired. International Journal of Current Advanced Research. 2019; 8(6):19338-19343. doi: 10.24327/ijcar.2019.19343.3725.

4. Eschenbeck H, Gille V, Heim-Dreger U, Schock A, Schott A. Daily Stress, Hearing-Specific Stress and Coping: Self-reports from Deaf or Hard of Hearing Children and Children With Auditory Processing Disorder. Journal of Deaf Studies and Deaf Education 2017;22(1):49-58. doi:10.1093/deafed/enw053.

5. Kumari R, Tiwari S, Kumar S. Prevalence of stress among parents having Hearing Impaired child in North India. World Journal of advance Healthcare Research 2020;4(2):110-114.

6. Leiner M, Argus-Calvo B, Peinado J, Keller L, Blunk DI. Is there a need to modify existing coping scales to include using electronic media for coping in young people? Frontiers in Pediatrics 2014;2:127. doi:10.3389/fped.2014.00127

7. Movallali G, Amiri M, Yousefiafrashteh M, Morovati Z. Prental stress and Mental Health in Mothers of Children with Hearing Impairement: The effectiveness of a Behavioural Training Program. IOSR Journal of humanities and social science (IOSR-JHSS) 2015;20(7):89-95. DOI: 10.9790/0837-20758995. 
8. Notash FD, Elhamkia E. Comparing loneliness, depression and stress in students with hearing impaired and normal students studying in secondary schools of Tabriz. International Journal of Humanities and cultural studies 2016, 1711-1719.

9. Prakash SS, Prakash SGR, Ravichandran A, Susan KY, Alex W. Measuring Levels of stress and depression in mothers of children using hearing aids and cochlear implants: A Comparative study. International Journals of Special Education 2013;28(1):37-44.

10. Prout TF. Stress and Coping in families with Deaf Children. Pennsylvania State University 2014, 155-166.

11.Zaidman-Zait A, Most T, Tarrasch R, Haddad-Eid E, Brand D. The impact of childhood hearing loss on the family: mothers' and fathers' stress and coping resources. Journal of Deaf Studies and Deaf Education. 2016; 21:23-33. DOI:10.1093/deafed/ env038.

12. Zaidman-Zait A, Dotan A. Everyday Stressors in Deaf and Hard of Hearing Adolescents: The Role of Coping and Pragmatics. Journal of Deaf Studies and Deaf Education. 2017;22(3):257-268.

doi:10.1093/deafed/enw103.

13. Seiffge-Krenke I, Weidemann S, Fentner S, Aegenheister N, Poeblau M. Coping with school-related stress and family stress in healthy and clinically referred adolescents. European Psychologist 2001;6:123-132.

Doi: 10.1027//1016-9040.6.2.123

14. Most T, Ingber S, Heled-Ariam E. Social competence, sense of loneliness, and speech intelligibility of young children with hearing loss in individual inclusion and group inclusion. Journal of Deaf Studies and Deaf Education 2012;17:259-272.

Doi:10.1093/deafed/enr049. 